\title{
Effect of Microstructure on Fatigue Properties of Several Ti-Alloys for Aerospace Application
}

\author{
A. El-Chaikh*, A. Danzig and D. Muenter \\ Liebherr-Aerospace Lindenberg GmbH, Pfaenderstrasse 50-52, 88161 Lindenberg, Germany \\ *ali.el-chaikh@liebherr.com
}

\begin{abstract}
$\underline{\text { Abstract }}$
A wide range of available Ti-alloys is used at Liebherr-Aerospace Lindenberg $G m b H$ for several aeronautical applications in flight controls and landing gear systems. For these applications, the mechanical properties of conventionally manufactured Ti-alloys $(\alpha+\beta$, near $\beta)$ as well as additive manufactured Ti-alloy were optimized.

Modification of the heat treatment parameters of a near- $\beta$ titanium alloy leads to optimization of the hardening process of large cross-sections. This modification allows the adjustment of an optimum volume fraction of the primary $\alpha$-phase resulting in enhancing of the elongation, fracture toughness and fatigue properties.
\end{abstract}

For a fatigue critical forging part from $(\alpha+\beta)$-alloy a slight modification of the chemical composition combined with an additional heat treatment step during the forging process was performed. The adjusted microstructure of the modified process exhibits better fatigue behavior when compared to the conventional microstructure.

Ti6A14V parts produced by Additive Manufacturing, printed with optimized parameters and followed by heat treatment will result in reasonable fatigue properties in all printing directions, reducing the anisotropy of the printed parts.

These improvements bring Liebherr-Aerospace Lindenberg GmbH in the position to adapt the used titanium alloys for the needs in a wide range.

For the evaluation of the microstructure, light and scanning electron microscopes were used. Furthermore a model described in the "Metallic Materials Properties Development and Standardization" (MMPDS) was modified and used for the evaluation of the fatigue results.

\section{Introduction}

For applications in landing gears and flight controls, titanium alloys are highly preferred, since they exhibit the highest specific strength among metallic alloys at temperatures below $200^{\circ} \mathrm{C}$ and an excellent corrosion resistance. At LiebherrAerospace Lindenberg $\mathrm{GmbH}$ several titanium alloys are used for aeronautical applications in flight controls and landing gear systems.

Ti6Al4V is the most common alloy among the titanium alloys. For aeronautical applications it mostly used in the annealed condition according to the AMS4928 [1]. However, the tensile properties of Ti6Al4V and the hardenability are inferior to those obtained for beta titanium alloys. Therefore, Ti6Al4V is currently not more the dominant alloy for aerospace application [2]. Ti10V2Fe3Al is a near-beta titanium-base alloy and capable by means of heat treatment of attaining a wide 
variety of strength levels and microstructures. Furthermore, it exhibits an excellent forgeability and high hardenability [3]. It can be readily precision forged (hot die or isothermal) about $110{ }^{\circ} \mathrm{C}$ lower than Ti6Al4V, resulting in lower cost die materials. However, Ti10V2Fe3Al has to be water quenched after solution treatment, since this alloy lies directly on the Msline of the phase-diagram (figure 1) and leans to form martensite at slow cooling rates. The Ms-line presents the boundary line for the formation of martensite. If the amount of the $\beta$-stabilizing elements is further increased, $\beta$ does not transform longer to martensite upon fast quenching. Ti5Al5V5Mo3 $\mathrm{Cr} 1 \mathrm{Zr}$ is more beta stabilized than Ti10 $22 \mathrm{Fe} 3 \mathrm{Al}$ and characterized by a high hardenability and high tensile properties. It is a modification of Ti5 $\mathrm{A} 15 \mathrm{~V} 5 \mathrm{Mo} 3 \mathrm{Cr}$, which has been developed as a substitute for Ti10V2Fe3Al alloy.

In the last years, different technologies for additive manufacturing (AM) of metal parts were introduced [4]. Laser powder bed fusion (L-PBF) of metals is one established technology with a certain degree of high industrial maturity. It allows production of parts with significant weight reduction, integration of functionality and hence reduction of number of parts and effort for assembly and maintenance. For serial production, Liebherr-Aerospace Lindenberg GmbH qualified a laser-based machine for powder bed fusion of metal powders in 2017 and started production of flying parts in 2018.

In this paper, a comparison of the fatigue behaviour of these alloys in some applications will be presented.

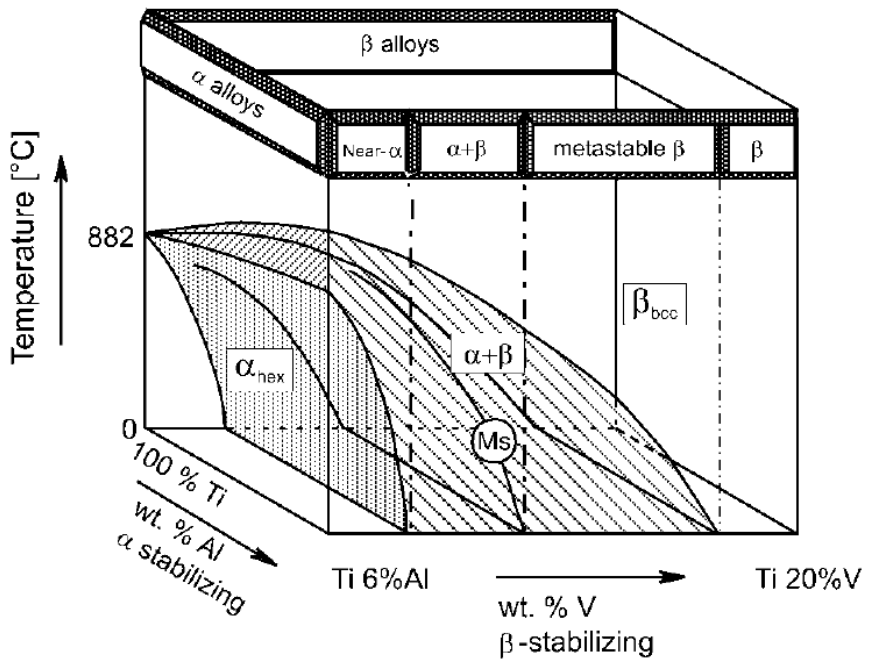

Figure 1: Three-dimensional phase-diagram to classify titanium alloys [5]

\section{Experimental}

\section{Investigated alloys}

Both beta titanium alloys used in this investigation Ti10V2Fe3Al and Ti5A15V5Mo3 $\mathrm{Cr} 1 \mathrm{Zr}$ were received in the form of forged billets. The billets were heat treated at Liebherr-Aerospace Lindenberg GmbH. The heat treatment consists of a solution annealing below the beta transus, in order to adjust a defined volume fraction of primary alpha followed by an aging. Furthermore the $(\alpha+\beta)$-alloy Ti6Al4V was used in this investigation in several variations: 
1. Ti6Al4V in annealed condition according to AMS4928 [1]

2. Ti6Al4V-modified. In this case, a heat treatment step was integrated during the forging process in order to modify the microstructure and achieve a defined volume fraction of globular alpha. For this purpose, an adjustment of the chemical composition was essential.

3. Ti6Al4V additive manufactured (AM) by means of laser-based powder bed fusion. For this purpose Ti6Al4V wire according to AMS4928 [1] was plasma atomized resulting in spherical particles. The powder particles, used for printing in the AM-system, have a mean size of about $40 \mu \mathrm{m}$.

Liebherr-Aerospace Lindenberg $\mathrm{GmbH}$ uses an AM-system equipped with a single 400W laser and build area with size $250 \times 250 \mathrm{~mm}$. AM parts are build up with $60 \mu \mathrm{m}$ layers. The production process is based on parameters supplied from the machine manufacturer and were optimized to improve productivity and part quality. The qualified process chain includes:

- stress relieve to minimize internal stresses before parts are removed from the Ti6Al4V building platform

- hot isostatic pressing (HIP) to close defects and increase volume fraction of $\beta$-phase

- surface treatment to smooth surfaces and

- milling of part interfaces with high requirements with respect to accuracy and surface quality

Melt pool monitoring and OT (optical tomography) monitoring were installed for online process control. Additionally a so-called powder bed camera controls the state of the powder bed after recoating of a powder layer and after exposure. During process qualification, material properties of AM-Ti6A14V were investigated in detail.

\section{Microstructure analysis}

Samples used for the microstructure analysis of all alloys were prepared by standard techniques and etched with a solution composed of $2 \mathrm{ml} \mathrm{HF}, 8 \mathrm{ml} \mathrm{HNO}_{3}$ and $90 \mathrm{ml} \mathrm{H}_{2} \mathrm{O}$. Martensitic microstructure of the AM-Ti6Al4V cannot be etched by means of this solution. In this case, the depiction of the $\alpha$-phase is achieved by a titanium-color etching solution composed of $1 \mathrm{~g}$ $\mathrm{H}_{5} \mathrm{~F}_{2} \mathrm{~N}, 25 \mathrm{ml}$ ethanol and $500 \mathrm{ml} \mathrm{H}_{2} \mathrm{O}$. The microstructure analysis was performed by means of a light microscope and a scanning electron microscope equipped with secondary electron (SE) and backscattered electron (BSE) detectors.

\section{Fatigue}

The geometry used for the axial fatigue specimens fulfills the requirements of ASTM E466 [6] with a gauge diameter of $8 \mathrm{~mm}$ (figure 2). The specimens were taken from the heat-treated billets. The additive manufactured axial fatigue specimens have a similar geometry with a diameter of $6 \mathrm{~mm}$ in the gauge section. For this purpose, testing bars with a diameter of $17 \mathrm{~mm}$ were printed in two different orientations, built up vertically and horizontally. The bars were treated according to the above mentioned process chain (stress relieved and hipped) and machined to produce unnotched samples with diameter of $6 \mathrm{~mm}$ and fine turned surface, taking into account the size effect of the tested specimens. Actions are ongoing to verify the impact of larger sample diameter, which may result in lower fatigue lives. 


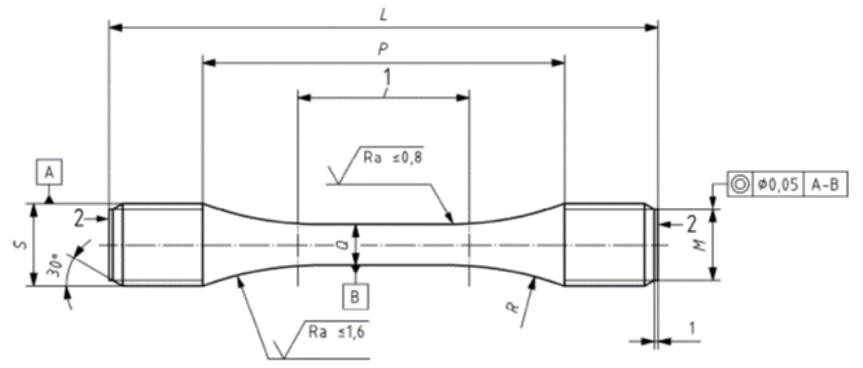

Figure 2: Geometry of the fatigue specimen used for the investigation in this paper

Fatigue tests were performed at a stress ratio of $\mathrm{R}=-1$ and room temperature. For the determination of the $\mathrm{S}-\mathrm{N}$ (stress versus number of cycles to failure) curves, a defined number of fatigue tests on specimens taken from different heats in different directions (L: longitudinal and LT: transversal longitudinal) were performed. For the additive manufactured Ti6Al4V tested fatigue specimens were built in different jobs and directions.

Taking into account that the S-N curve predominantly shows a non-linear behavior up to the fatigue limit, also in the double logarithmic scale, the entire curve is described with a model (equation 1) according to the "Metallic Materials Properties Development and Standardization" (MMPDS) [7].

$$
\log \mathrm{N}=\mathrm{C}_{1}+\mathrm{C}_{2} \cdot \log \left(\mathrm{S}-\mathrm{C}_{3}\right)
$$

With $\mathrm{C}_{1}>0, \mathrm{C}_{2}<0$ and $\mathrm{C}_{3} \geq 0$ ( $\mathrm{N}$ : cycle number, $\mathrm{C}_{1}, \mathrm{C}_{2}, \mathrm{C}_{3}$ : material specific parameters, $\mathrm{S}$ : stress amplitude).

The model according to the MMPDS cannot be extrapolated to the low cycle fatigue (LCF) region. To obtain a continuous description of the S-N curve from the low cycle up to the high cycle fatigue (HCF) region, a modified goniometric model (MGM) according to equation 2 [8] was used for fatigue behavior description of the forging parts made from the Ti6Al4V.

$$
\log \mathrm{N}=\mathrm{C}_{1}+\mathrm{C}_{2} \cdot \tan \left(\mathrm{C}_{3}+\mathrm{C}_{4} \cdot \mathrm{S}\right)
$$

$\left(\mathrm{N}>0.25\right.$ : cycle number, $\mathrm{C}_{1}, \mathrm{C}_{2}, \mathrm{C}_{3}, \mathrm{C}_{4}$ : material specific parameters, $\mathrm{S}>0$ : stress amplitude).

The stress levels in SN-curves are given in relative values, which is arbitrarily but constantly chosen for all diagrams. 


\section{$\underline{\text { 3. Results and Discussion }}$}

Table 1 shows the minimum tensile properties of the titanium alloys used for the comparison in this paper. Ti5A15V5Mo3Cr1Zr exhibits the highest strength. Ti6A14V, AM-Ti6A14V and Ti6Al4V-modified fulfill the requirements in the AMS4928.

Table 1. Minimum tensile properties of the titanium alloys used in this paper

\begin{tabular}{|l|l|l|l|l|}
\hline Material & condition & $\mathrm{R}_{\mathrm{m}}[\mathrm{MPa}]$ & $\mathrm{R}_{\mathrm{p} 0.02}[\mathrm{MPa}]$ & $\varepsilon[\%]$ \\
\hline Ti10V2Fe3Al & STA & 1103 & 993 & 4 \\
\hline Ti5A15V5Mo3Cr1Zr & STA & 1240 & 1170 & 4 \\
\hline Ti6A14V & annealed & 896 & 827 & 8 \\
\hline Ti6A14V modified & annealed & 896 & 827 & 8 \\
\hline AM-Ti6A14V & stress relieved and HIP & 931 & 862 & 10 \\
\hline
\end{tabular}

Comparison of the fatigue behavior of Ti10V2Fe3Al and Ti5Al5V $5 \mathrm{Mo} 3 \mathrm{Cr} 1 \mathrm{Zr}$

In landing gear systems forging parts with thick sections require high specific strengths. For such an application, two beta Ti alloys were investigated. Both alloys were received as billets and exhibit globular primary $\alpha$-phase with a size between 2$5 \mu \mathrm{m}$. The heat treatment to STA-condition (solution treated and aged) of both alloys consists of a solution treatment at temperatures below the beta transus temperature and an aging at lower temperatures.

Water quenching of parts from Ti10V2Fe3Al with thick sections causes a reducing of the elongation. Preliminary investigations at Liebherr-Aerospace Lindenberg $\mathrm{GmbH}$ showed that, in thick sections the volume fraction of primary alpha influences the fracture toughness and the elongation of this alloy. Therefore, Ti10V2Fe3 Al was heat treated with defined parameters, in order to achieve a certain volume fraction of primary alpha.

The morphology of the primary alpha is defined by the alpha-beta work. High deformation leads to globular primary alpha and too much deformation would result in high ductility and unacceptable toughness [9]. However, reduction of the deformation during working in the $\alpha+\beta$ region will result in elongated primary alpha. This will give also a tendency to precipitate alpha on the grain boundaries. In this study, the heat treatment parameters are chosen in such a way, that the influence of the elongated and globular alpha on the mechanical properties is negligible. Ti5Al5V5Mo3 $\mathrm{Cr} 1 \mathrm{Zr}$ was heat treated with parameters resulting in much lower volume fraction of the primary alpha. Figure 3 shows the fatigue behavior of the two beta titanium alloys. 

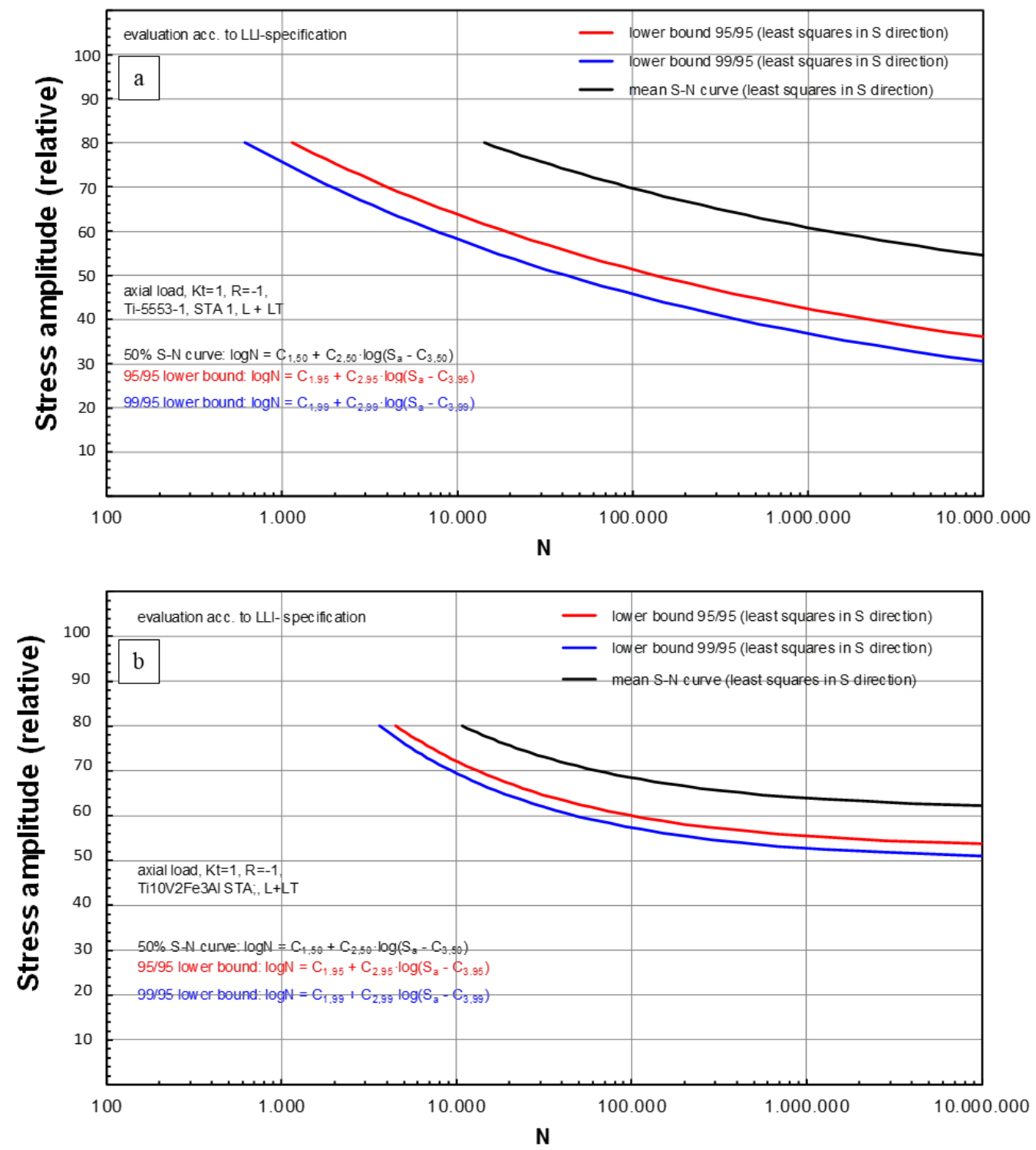

Figure 3: S-N curves of two beta titanium alloys in STA-condition a) Ti5Al5V5Mo3Cr1Zr and b) Ti10V2Fe3Al

The superior fatigue behavior of Ti10V2Fe3Al compared to Ti5Al5V5Mo3 $\mathrm{Cr} 1 \mathrm{Zr}$ can be explained by the following microstructural features:

1. Different volume fraction of the primary alpha: Ti10V2Fe3Al is heat treated to have a high volume fraction of the primary alpha. Preliminary tests at Liebherr-Aerospace Lindenberg $\mathrm{GmbH}$ and data from literature $[10,11]$ showed 
that different volume fraction lead to different fatigue behavior. Varying the volume fraction of the primary alpha results also in different volume fractions and different morphologies of the secondary alpha. Investigations are ongoing to check, if same volume fraction of the primary alpha in both alloys results also in same morphology of the secondary alpha. This will lead to better comparison of both alloys and show also, if higher volume fraction of the primary alpha results in better fatigue behavior for Ti5Al5V5Mo3 $\mathrm{Cr} 1 \mathrm{Zr}$

2. Precipitation density: the higher precipitation density and the finer distribution of the secondary alpha in the fully precipitated matrix in Ti10V2Fe3Al (figure 4a) leads to a delay of the crack initiation during fatigue.

3. Free precipitation regions in Ti5Al5V $5 \mathrm{Mo} 3 \mathrm{Cr} 1 \mathrm{Zr}$ : Free precipitation regions in the matrix of $\mathrm{Ti} 5 \mathrm{Al} 5 \mathrm{~V} 5 \mathrm{Mo} 3 \mathrm{Cr} 1 \mathrm{Zr}$ (figure $4 \mathrm{~b}$ ) exhibits lower hardness than the precipitated matrix. In spite of the small size of these regions, they may act as crack initiation sites during HCF resulting in higher scattering of fatigue results and a drop of the lower bound curves. A solution treatment above the beta transus temperature followed by a duplex aging may lead to more homogenous precipitation of the $\beta$-matrix and hence to elimination of the free precipitation regions [10, 12] in Ti5Al5V5Mo3Cr1Zr.
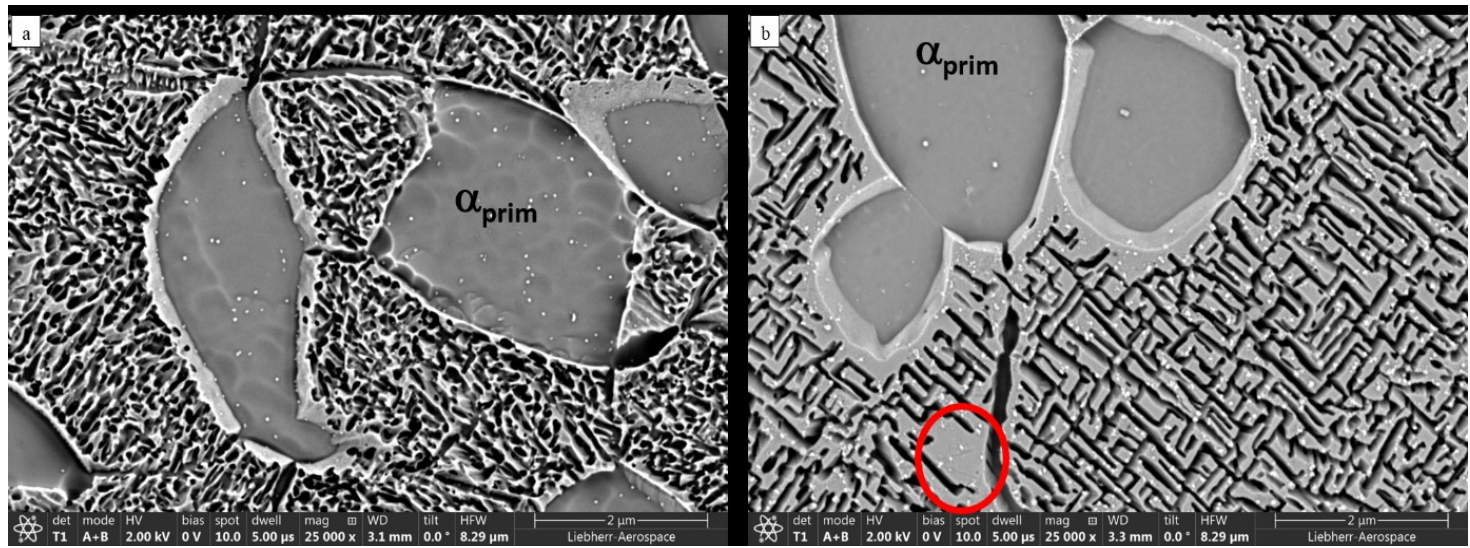

Figure 4: SEM micrographs with BSE-Detector showing at high magnification the microstructure of a) Ti10V2Fe3 $\mathrm{Al}$ and b) Ti5Al5V5Mo3Cr1Zr; marked area shows free precipitation region

\section{Comparison of the fatigue behavior of Ti6Al4V and Ti6Al4V-modified}

For a fatigue critical forging part with a wall thickness of about $95 \mathrm{~mm}$ a new variation of the $(\alpha+\beta)$-alloy Ti6Al4V (Ti6Al4V-modified) was developed in a joint effort between Liebherr-Aerospace Lindenberg GmbH and a titanium forging supplier. A slight adjustment of the chemical composition (but still within the requirements of the AMS4928) combined with an additional heat treatment step during the forging process was performed. The improved microstructure of the modified process exhibits better fatigue behavior and smaller scattering (figure 5), when compared to the conventional microstructure. The microstructure of the conventional Ti6Al4V is a dual phase globular microstructure with a small fraction of isolated $(\alpha+\beta)$-lamellar colonies between nearly equiaxed and connected $\alpha$-grains. The volume fraction of the $\alpha$-phase in the conventional microstructure is in the range of $80 \%$. Due to the heat treatment step, the modified microstructure exhibits a reduced volume fraction of the globular $\alpha$-phase with Widmanstaetten plates of the $\alpha$-phase in the $\beta$-matrix. 

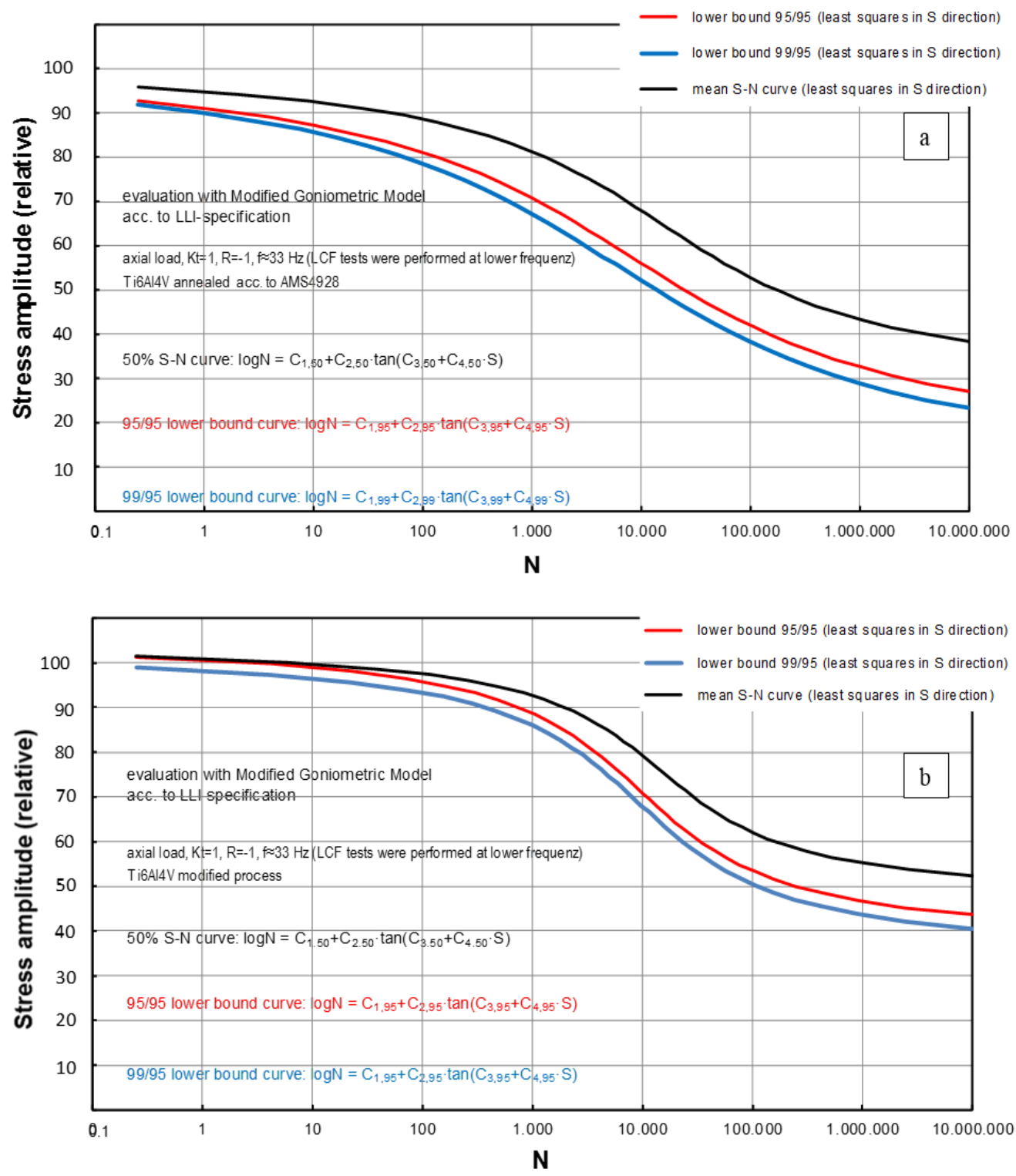

Figure 5: Determined S-N curves for a forging part in landing gear system made of a) conventional Ti6Al4V and b) Ti6Al4Vmodified

Comparison of the fatigue behavior of AM-Ti6Al4V and Ti6Al4V

Figure 6 shows the microstructure development of Ti6Al4V parts during the additive manufacturing process starting from the powder, followed by a stress relieving and lastly HIP at a temperature below the beta-transus. Figure $6 \mathrm{a}$ and figure $6 \mathrm{~b}$ 
show powder particles and the cross section of a powder particle, respectively. After printing the material reveals a martensitic microstructure with $\alpha$-Phase. Since the amount of the retained $\beta$-phase is defined by the cooling rate, the microstructure consists completely of $\alpha^{\prime}$-phase. The microstructure shows no change in the $\alpha^{\prime}$-grains morphology or size even at high distance from the buildingplate. Stress relieving has no big impact on the microstructure, irrespective of a slightly growth of the $\alpha$-laths (figure $6 \mathrm{c}$ ). Figure $6 \mathrm{~d}$ shows the microstructure after HIP, which consists of recrystallized and elongated $\alpha$-grains embedded in $\beta$-phase grain boundaries.
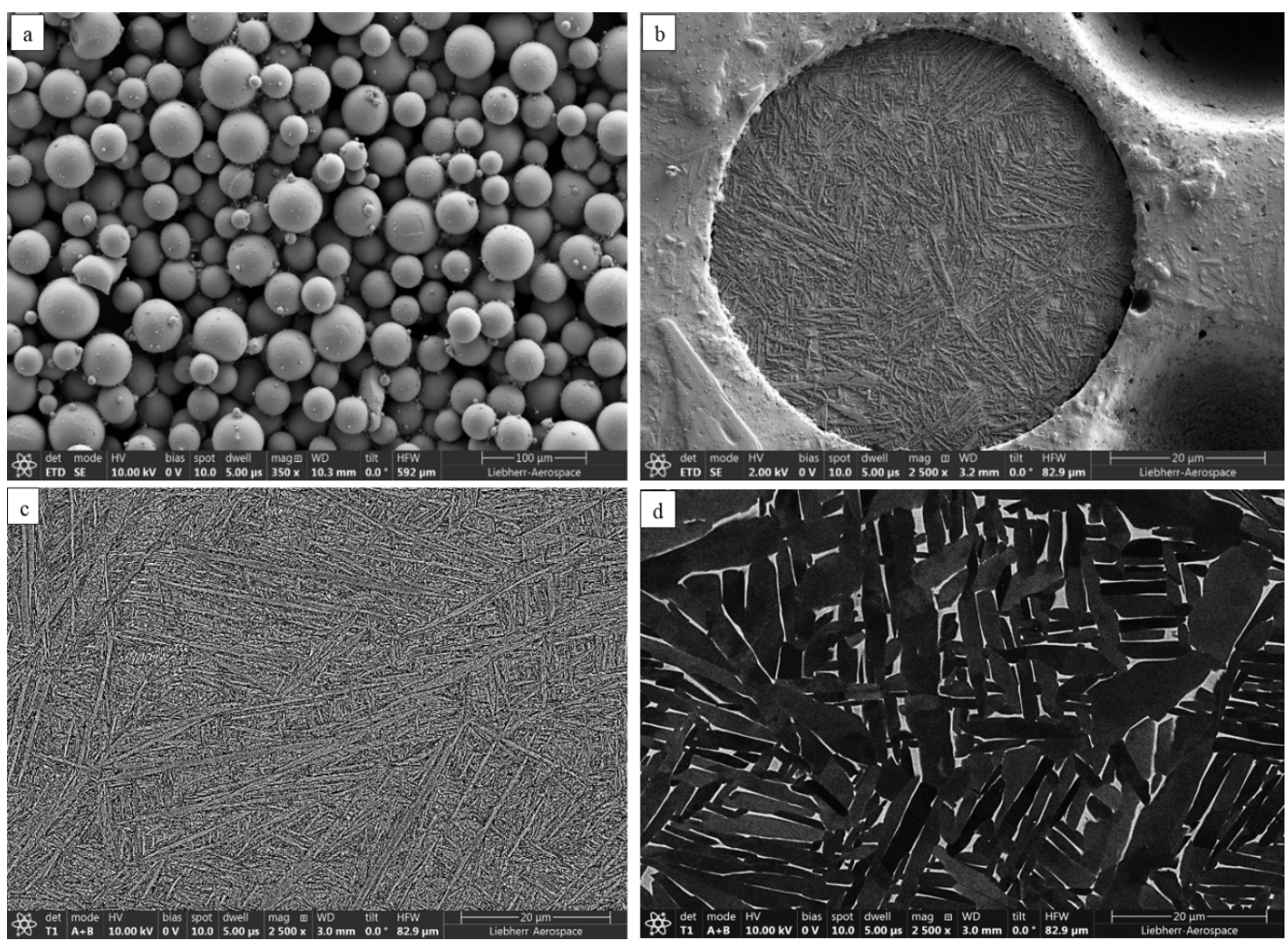

Figure 6: SEM micrographs of a) Ti6Al4V powder with a mean particle size of about 50 $\mu \mathrm{m}$, b) cross section of Ti6Al4V-powder showing $\alpha^{\prime}$ martensite needles, c) $\alpha^{\prime}$ martensitic microstructure of Ti6Al4V parts produced by additive manufacturing after stress relieving and d) final microstructure of additive manufactured Ti6Al4V parts (after HIP) showing $\alpha$-grains (dark) embedded in $\beta$ phase grain boundaries (bright).

The $\alpha$-laths thickness increases considerably after HIP and a certain volume fraction of the $\beta$-phase is available. Compared to the martensitic microstructure with $\alpha^{\prime}$-phase, $(\alpha+\beta)$-microstructure exhibits improved ductility and lower strengths. The improvement of ductility can be attributed to the addition of the $\beta$-phase by means of transformation of $\alpha^{\prime}$ to $(\alpha+\beta)$. This is due to the increase in ease of slip transfer between the $\alpha$ - and $\beta$-phases compared to that of the martensite $\alpha^{\prime}$-phase. Two primary slip systems of the $\alpha$-phase are aligned with the $\{110\}\langle 111\rangle$ and $\{112\}\langle 111\rangle$ systems of the $\beta$-phase, with a third set misoriented at a low angle and thus, slip transfer across the two phases can occur [13]. 
The obtained microstructure (up to a wall thickness of $17 \mathrm{~mm}$ ) results in similar tensile properties for different print orientations and high fatigue properties. For this wall thickness HIP is able to eliminate internal defects occurring during layer-wise part generation, resulting in a microstructure which differs from the microstructure of conventional Ti6Al4V-bars in annealed condition. The S-N curves (figure 7) are comparable to conventionally produced Ti6Al4V (fatigue specimens were taken from bars with $\varnothing 25 \mathrm{~mm})$ in annealed condition.

Figure 8 shows the crack initiation site in a AM-Ti6Al4V fatigue specimen. Even if the crack initiates at such eliminated failure, the specimen shows high fatigue life. 

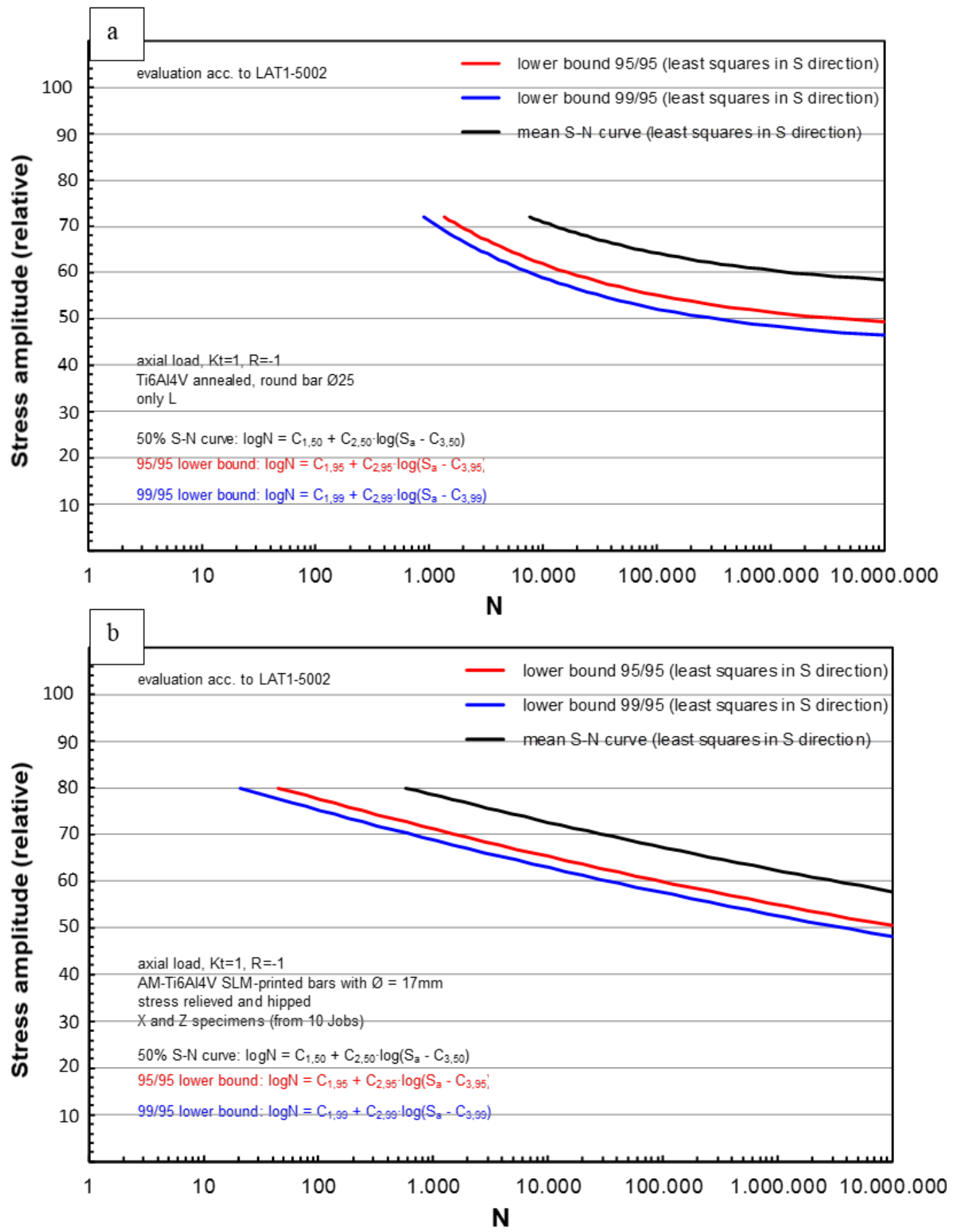
Figure 7: S-N curves of a) Ti6Al4V in annealed condition according to AMS4928, samples taken from round bars with Ø25mm and b) AM-Ti6Al4V, samples taken from printed in 10 different jobs, stress relieved and hipped bars with $\emptyset 17 \mathrm{~mm}$
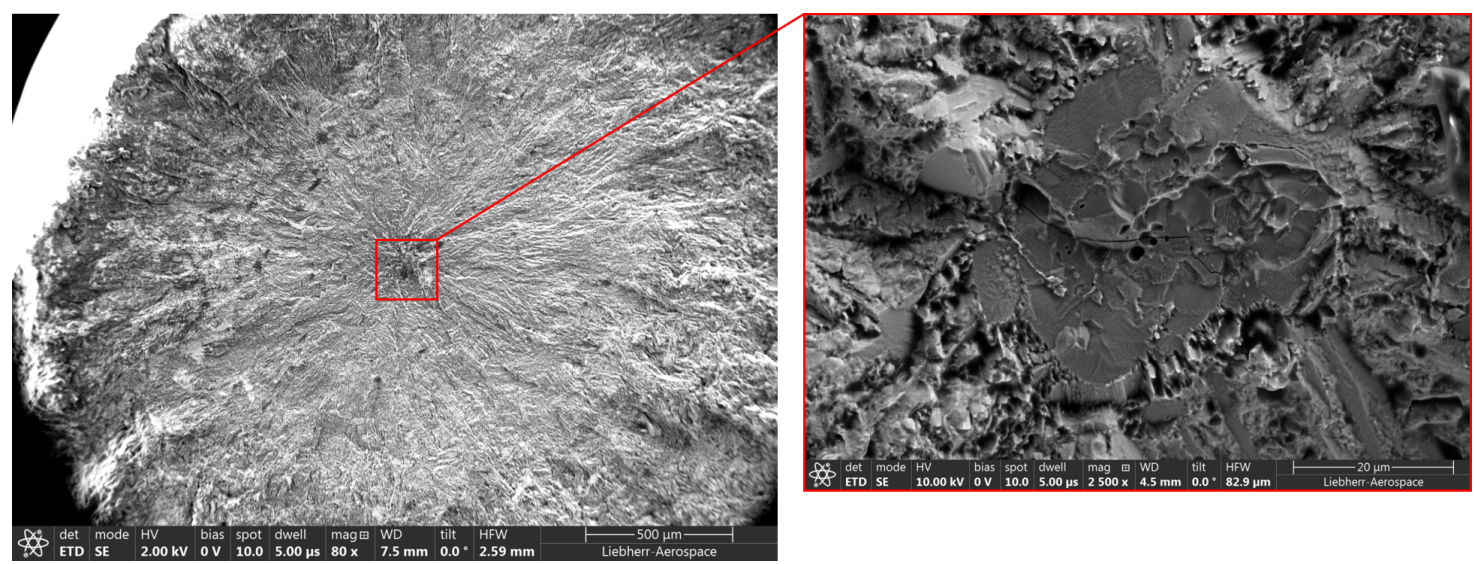

Figure 8: Crack initiation site on a fatigue specimen from AM-Ti6Al4V with high fatigue life

\section{Conslusion}

1. For beta titanium alloys the adjustment of an optimum volume fraction of primary alpha leads to high fatigue properties.

2. Precipitation free zones in beta titanium alloys are potential sites for crack nucleation resulting in lower fatigue behaviour.

3. Forged parts from Ti6Al4V can be also modified to reach high fatigue properties by means of a slight modification during the forging process resulting in a different microstructure.

4. For additive manufactured Ti6Al4V optimization of the printing parameters and a heat treatment combined with HIP lead to good fatigue behaviour, which is comparable with rolled or forged bars in the high cycle fatigue region.

\section{References}

[1] SAE AMS 4928, Titanium Alloy Bars, Wire, Forgings, Rings, and Drawn Shapes 6Al - 4V Annealed

[2] R.R. Boyer and R.D. Briggs, JMEPEG J. Mater. Eng. Perform, 14 (2005) 681-685

[3] R.R. Boyer and G.W. Kuhlman, Metallurgical Transactions A, 18A (1987) 2095-2103

[4] T. Wohlers, Wohlers Report, Part 2 (2019)

[5] C. Leyens and M. Peters, WILEY-VCH Verlag GmbH \& Co. KGaA, (2003) 1-36

[6] ASTM E466 Standard Practice for Conducting Force Controlled Constant Amplitude Axial Fatigue Tests of Metallic Materials (2015) 
[7] Metallic Materials Properties Development and Standardization (MMPDS), Battelle Memorial Institute (2008)

[8] H.J. Schäfer, P. Beiss, C. Broeckmann, proceedings of Fifth International Conference on Very High Cycle Fatigue, DVM, (2011) 519-524

[9] G. Terlinde, H.-J. Rathjen \& K.-H. Schwalbe, Metallurgical Transactions A, 19A (1988) 1037-1049

[10] L. Wagner \& J. K. Bigoney, in Titanium and Titanium Alloys, C. Leyens and M. Peters, WILEY-VCH Verlag GmbH \& Co. KGaA, (2003) 153-185

[11] S.K. Jha, K.S. Ravi Chandran, Scripta Materialia, 48 (2003) 1207-1212

[12] El-Chaikh, A., Schmidt, P., Christ, H.-J, Procedia Engineering, 2 (2010) 1973-1982

[13] Simonelli, M., Tse, Y. Y. and Tuck, C., Materials Science and Engineering A. 616 (2014) 1-11 